\title{
Scientific Basis for Modeling and Calculation of Acoustic Vibrations in the Nuclear Power Plant Coolant
}

\author{
Proskuryakov KN* \\ Moscow Power Engineering Institute, National Research University "MPEI", Russia
}

Submission: April 04, 2017; Published: June 19, 2017

*Corresponding author: Proskuryakov KN, Moscow Power Engineering Institute, National Research University "MPEI”, Moscow, Russia, Email: ProskuriakovKN@mpei.ru

\begin{abstract}
Created new scientific direction "Diagnosis, prognosis and prevention of vibration - acoustic resonances in the NPP equipment It is shown that the developed methods can be used to predict and prevent the occurrence of vibration -acoustic resonances in the NPP equipment. It is shown that the volume of pressurizer at NPPs with VVER and PWR as well as boiling water reactor exploded at Japan's NPP Fukushima Daiichi 1 represent them self a Helmholtz resonators, which contain water and steam volumes and able many times increases the impact on them of outside periodic oscillations,. Worked out results also could be useful in another industrial technologies based on applications of single and two-phases flows including petrochemical, and oil/gas processing.
\end{abstract}

Keywords: Vibration-acoustic resonance; Helmholtz resonator; Electro-acoustic analogies; Acoustical models; Frequencies; Severe accident; Equipment; Pipe

\section{Introduction}

In the mid1960s when the nuclear technology has emerged beside other energy sources, in the NRU "MPEI" at the Department of Nuclear Power Plants created new scientific direction "Diagnosis, prognosis and prevention of vibration - acoustic resonances in the NPP equipment." Currently, the interactions of the equipment vibrations with the vibrations of the coolant at the plant studied not enough. The reason of this is underestimating the complexity of interacting processes, the description of which is possible only within the framework of interdisciplinary research. Developed by us the acoustic models of coolant in the NPP equipment, and analysis of these models are based on the use of the knowledge of several sciences: thermal hydraulics, neutron physics, acoustics, gas dynamics, mechanics, the theory of radio circuits and theoretical foundations electrical engineering. The priority is confirmed in the justification of the methods for modeling the natural oscillations of the coolant pressure in a single- and two-phase state, including self-oscillations and parametric oscillations. For the first time, methods, algorithms and calculations have been developed, quantitative estimates have been made: the range of the natural frequencies of pressure oscillations of the coolant; Q-factor of cooling systems; the so-called bandwidth [1]. The validity of the method of electro acoustic analogies for calculating the parameters of NPP systems with singlephase and two-phase coolant is substantiated. An important stage in the development of methods for analyzing the acoustic systems of a coolant at NPPs is to study the electro acoustic analogy with a one-dimensional two-phase pulsating medium flow. For prediction and prevention resonances of vibration with acoustical oscillation of coolant need to know the natural frequency oscillations of the equipment and its elements and their compounds, as well as the natural frequency of the coolant pressure oscillation (NFCPO) in a variety of operational and emergency modes.

The practice of operating NPPs (NPPs) shows that flows of coolant induce mechanical vibrations of the equipment and its components vibration was found to be one of the most important factors that cause damages to some parts of these power plants. The damage and possible causes were documented by researchers and governmental institutions [2]. In improved the possibility of a thermal-hydraulic instability (self-oscillation) in a single steam generating channel and their effect on the reduction of the critical heat flux by increasing the length of the evaporation area. Article translated into English and published in the United States, its content is reflected in [3]. which systematized publication, selected to be the new knowledge to the study of boiling crises and critical heat fluxes. 
The article [2] proved the physical nature of occurrence of self-oscillations of the flow rate in a single steam generating channel, the frequency of which is the natural frequency of the fluid contained in it. It is shown that a strong decrease of the critical heat flux occurs at high steam content and due to increased evaporation portion length.

It is this effect, as specified in [4], has led to the destruction of the reactor at the Chernobyl NPP. "The continuing decline of water flow through the technologic channels (TC) reactor under the power growth conditions had led to an intensive steam generation, and then the crisis of heat transfer, heating fuel, its destruction, the rapid boiling of coolant, which were particles of the destroyed fuel, a sharp increase in pressure in the TC, their destruction, and heat explosion that destroyed the reactor and the part of building structures and led to the release of fission products into the environment.

\section{About Severe Accidents At Npps Tmi, Chernobyl and Fukushima Daiichi}

In pursuance of the instruction of the Council of Ministers of the USSR, PP-8768 from 18.05.86, the first persons of ministries and departments working on nuclear issues considered expert conclusions of the author of this article. The Gosatomnadzor of the USSR, taking into account consultations with specialists from the National Research Center Kurchatov Institute and the Scientific Research Institute of Power Engineering (NIKIET) were reported to the Council of Ministers:

A. Proposition of K. Proskuryakov to the Interdepartmental Technical Council for the NPP to clarify the existing concept of the Design Basis Accident (DBA) is correct. The initial event and the way of development of the accident, supposed by the author, are potentially possible and should be analyzed by the Scientific Supervisor, the Chief Designer and the General Designer of the NPP.

B. The author of the proposals rightly points out the need to accelerate the introduction of a system of monitoring and operating diagnostics of the equipment being used, using, in particular, the monitoring of the condition of the coolant.

C. It is necessary to accelerate the work on the implementation of proposals to the Ministry of Energy to equip NPPs with vibroacoustic diagnostics.

D. Gosatomnadzor supports the recommendations of $\mathrm{K}$. Proskuryakov to Ministry of Higher Education of the USSR on the need to create a specialization "Diagnosis of the technical condition of NPPs and maintenance of reliability and safety systems."

In Proskuryakov [5] for the first time is shown that if the increase in the two-phase flow velocity decreases the friction force, it leads to self-excited oscillations of pressure. Such conditions occur in the steam generating channel mass flow rates in the range corresponding to the falling portion of the hydrodynamic characteristics. This phenomenon must be considered as the main factor causing the multiple increases of dynamic loads on equipment during the flow of the DBA at NPP with VVER and PWR reactors. In more recent publications] noted the impact of this effect on the vibrations of pipelines [6] and steam generators reliability [7,8]. In [9], first proven that the eigen frequency of coolant pressure pulsations in emergency mode at the boiling stock in the reactor core is several times lower than the frequency corresponding to the normal operation mode. This change in pressure pulsation spectrum is diagnostic warning: of boiling in the core of VVER and PWR reactors. The accident at TMI occurred after the appearance of this information. If the staff of NPP TMI timely recognized the start of boiling in the reactor core, it could to prevent one of the most severe NPP accidents. In the same paper offered the acoustic model of the pressurizer, is used in NPP with VVER reactors (and their foreign counterparts - PWR). This model is used to calculate the frequency of the acoustic standing waves generated by the pressurizer $[10,11]$. In [12] is shown that the most important results in NRU "MPEI" have been published much earlier than abroad and could be used to prevent the development of catastrophic accidents at the Chernobyl NPP and NPPs, "Three Mile Island-2". It is shown that the volume of a pressurizer at a NPP with VVER and PWR represents itself as the Helmholtz resonator, which

contains of water and steam volumes, as well as reactor of exploded at Japan's NPP Fukushima Daiichi 1. It is shown that the developed methods can be used to predict and prevent the occurrence of vibro-acoustic resonances in the NPP equipment in the operating and emergency conditions, and also due to seismic impact. It is shown that the volume of pressurizer at NPPs with VVER and PWR is a Helmholtz resonator, which contained water and steam parts, can be many times increases the impact on it from outside periodic oscillations, as well, and the body type boiling water reactor NPP exploded at Japan's Fukushima Daiichi 1.

\section{Conclusion}

Scientific basis for modeling and calculation of acoustic vibrations can be used to predict and prevent the occurrence of vibration -acoustic resonances in the NPP equipment and also in another industrial technologies based on applications of single and two-phases flows including petrochemical, and oil/gas processing in the operating and emergency conditions, as well as seismic and impact.

\section{References}

1. Proskuryakov KN, Novikov KS, Moukhine VS, Novikov KS, Galivets Eyu, et al. (2009) Band Width of Acoustic Resonance Frequency Relatively Natural Frequency of Fuel Rod Vibration. Proceedings of Global congress 9485: 6-11 
2. Proskuryakov KN (1965) Self-Oscillation in a Single Steam Generating Duct. Thermal Engineering 12(3): 96.

3. Tong LS (1972) Boiling crisis and critical heat flux. Westinghouse Electric Corporation.

4. (1986) Information about the Chernobyl accident and its consequences, prepared for the IAEA. Atomic Energy 61(5): 301 - 320.

5. Proskuryakov KN (1975) Bedingungen Auftreten von Oszillationen in dem Dampferzeugungskanal. Kernenergiya.

6. Van Blarcom PP, Smitt RD (1979) Flashing fluids at low pressures, pp. 391-40.

7. Ovchinnikov VF, Smirnov LV (1981) Fluctuations of pipelines with non-stationary flow of liquid. Physics and technology of nuclear reactors 2: 3-11.

This work is licensed under Creative Commons Attribution 4.0 Licens

DOI: 10.19080/RAPSCI.2017.01.555577
8. Verezemsky VG, Smirnov LV, Ovchinnikov VF, Yaskelyan AV (1998) Influence of operating modes of circuits of the NPP circulation with VVER-1000 on the reliability of PGV-1000 steam generators, pp. 36-41.

9. Proskuryakov KN, Stoyanov SP, Nidtsballa G (1979) Theoretical definition of frequencies of self oscillations of the coolant in the first circuit of the NPPs. MPEI 407: 87-93.

10. Mullens LA, Thie JA (1983) Understanding Pressure Dynamic Phenomena in PWRs for Surveillance, Diagnostic Application Proceedings of 5th Power Plant Dynamics, Controls. Testing Symposium University of Tennesse, Knoxville.

11. Por G, Izsak Et, Valko S (1985) Some Results of Noise Measurements in PWR NPP. Progress in Nuclear Energy 15: 387.

12. Proskuryakov KN, Zaporozhets MV (2016) Development of methods of diagnosis, prognosis and prevention of vibration -acoustic resonances in NPPs equipment. Vestnik MPEI 5: 19-24.

\section{Your next submission with Juniper Publishers} will reach you the below assets

- Quality Editorial service

- Swift Peer Review

- Reprints availability

- E-prints Service

- Manuscript Podcast for convenient understanding

- Global attainment for your research

- Manuscript accessibility in different formats

( Pdf, E-pub, Full Text, Audio)

- Unceasing customer service

Track the below URL for one-step submission https://juniperpublishers.com/online-submission.php 